\title{
Hemi Chorea Associated With Hyperglycemia Benefitted From Barbiturate Therapy and Strict Glycemic Control
}

\author{
Samer N Roy*, Haroon Chaudhry, Shreya Sahay Saxena and Krishnakant Shah Aka Khandelwal \\ Internal Medicine, USA
}

Submission: June 12, 2017; Published: June 27, 2017

*Corresponding author: Samer N Roy, Internal Medicine 102 Thomas Rd, West Monroe, Lousiana 71291, USA, Tel: 518-512-1821; Email: hchaudhrymd@gmail.com

\begin{abstract}
Individuals with chronic and severe hyperglycemia can present with no symptoms to few non specific symptoms such as nausea, vomiting or abdominal pain [1]. Sometimes patients present with advanced nephropathy or neuropathy [2]. Here we present a case where an individual with long standing uncontrolled diabetes presented with an unusual presentation. He presented with uncontrolled and brisk jerking movement of his left hand. Immediately after starting the neurosuppresents and proper glycemic control patient reported decrease in intensity of these symptoms. Primidone decreases the nerve impulses in the nervous system and is a typical anti convulsing. Here we describe a case of hyperglycemia with an unusual clinical presentation that benefitted from a barbiturate.
\end{abstract}

Abbreviations: C-H-BG: Chorea-Hyperglycemia Basal Ganglia

\section{Introduction}

Chorea is a rapid, jerky, and irregular, movement that tends to occur in the distal limbs, or face, but may also occur in the proximal limb and axial structures. Chorea can occur in association with vascular disease, hypo- or hyper glycemia [3] and a variety of infections and degenerative disorders. Harrison 19th Hemichorea has been reported in patients with chronic uncontrolled diabetes. We report a similar patient who benefitted from controlling blood sugar levels and Primidone. Primidone belongs to a class of barbiturates and is classically used for focal seizures [4]. It is evident from our clinical experience that administration of Primidone in addition to proper sugar control patient was asymptomatic.

\section{Case Presentation}

A 54 year old Caucasian male complained of having 10 days of irregular, random, and non-rhythmic violent flinging movements in his left hand. Movements were jerky choreiform in nature, and had started 10 days ago when he was driving, slowly getting worse each day. The jerking movements were more intense and violent towards the end of the day when he would return from work, and would worsen when he was nervous. The patient's wife said that it stops when he is sleeping, but also reported he was unable to perform his day to day activities, such as tying his shoe laces or buttoning his shirt. The patient denied any memory problems, gait abnormalities, vision disturbances, sensory deficit, or confusion. However, the patient's past medical history is significant for hypertension, diabetes mellitus, anxiety disorder, tobacco use disorder, and myocardial infarction status post-CABG.

The family history is negative for any neurological disorder. Physical examination was unremarkable, except constant choreiform and dystonic movements involving his left hand. Cranial nerves were grossly intact, and his blood pressure was $131 / 68$, heart rate was $86 / \mathrm{min}$, respiratory rate was $18 / \mathrm{min}$, and temperature 98.3F. Random blood sugar level at the clinic was 454 . His home medications included Losartan 25mg; ones a day spell out Metformin 750mg twice a day out and Aspirin $325 \mathrm{mg}$ once a day. We ordered blood tests and imaging studies, and consulted neurology. We advised the patient to call for medical aid if he has fever, neck stiffness, headache, blurry vision, or gait difficulties.

At this time, differential diagnosis included hemorrhagic or ischemic stroke in the striatum, Huntington chorea, neoplasm, lupus, Wilson's disease, and C-H-BG (Chorea-Hyperglycemia basal ganglia). Laboratory studies revealed hyponatremia with 
sodium of $130 \mathrm{mEq} / \mathrm{l}$, hyperglycemia with glucose levels $434 \mathrm{mg}$ / $\mathrm{dl}$ and dyslipidemia with cholesterol $355 \mathrm{mg} / \mathrm{dl}$, triglyceride $588 \mathrm{mg} / \mathrm{dl}$, VLDL $118 \mathrm{mg} / \mathrm{dl}$, Cholesterol/HDL ratio of 8.7 , and HbA1C was 13.7. Moderate microalbuminuria was evident, and urgent MRI brain showed asymmetrical increased T1 signals within the right basal ganglia- primarily involving the caudate head and putamen (Figure 1). There was corresponding hypointensity on T2 imaging showing clustered tiny cyst-like spaces in the right frontal parasagittal periventricular white matter reflecting small remote infarct.

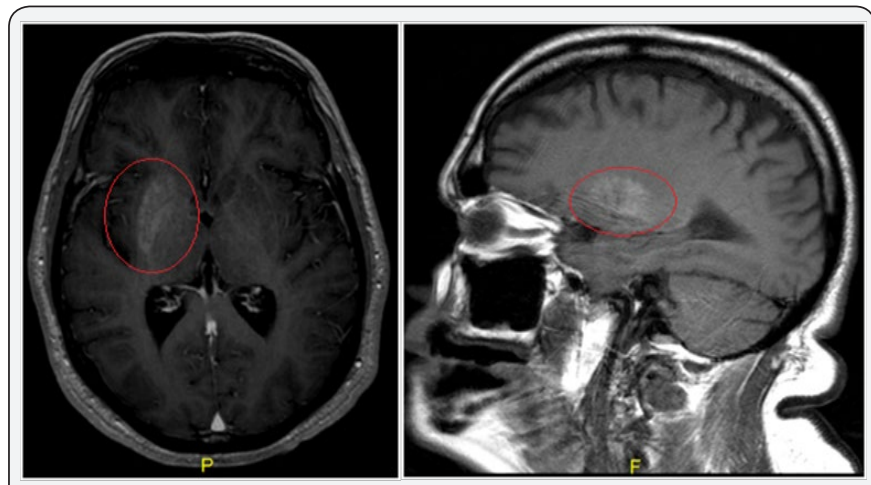

Figure 1: MRI of patient: T2 imaging showing hypointensity in right frontal parasagittal periventricular white matter.

Findings were consistent with hyperglycemic hemichorea hemiballismus. Patient came to the clinic after the tests were done and was advised to take Primidone 50mg ones a day, Insulin and Clonazepam $1 \mathrm{mg}$ every night. Patient was put on Clonazepam for him to cop up with the anxiety he was experiencing because of his new symptoms. C-peptide level was 3.95, so Carotid Doppler was ordered and it showed patent bilateral carotid arteries. Echocardiogram showed mild aortic valve sclerosis and LVEF of $50-55 \%$. We called the neurology department and ordered the consult, and their view was that the patient might have $\mathrm{C}-\mathrm{H}-\mathrm{BG}$ (Chorea-hyperglycemia basal ganglion) syndrome [5]. Patient has gradually improved with strict diabetes control, and it has nearly been a month since he reports improved chorea.

\section{Discussion}

The approach to patients with neurologic symptoms begins with focusing the clinical problem first in its anatomic and then in its path-physiological form. MRI of the brain was done to locate the site of the lesion. Chorea results specifically from disorders of the basal ganglion and so was it in our case. The basic pathphysiology of this disorder is reduced modulation of the basal ganglion by the sub thalamic nucleus. In majority of cases the excitatory output of the sub-thalamic nucleus is reduced, leading to a reduced inhibitory outflow of the basal ganglion. Without normal restraining the neurons are readily activated by inappropriate signal causing unrestricted abnormal movements. It has been associated with many conditions like encephalitis, hyperthyroidism, anticholinergic toxicity and other genetic and metabolic disorders. Long standing hyperglycemia is considered to be the etiology of this neurological clinical manifestation.
Treatment for this patient was challenging as well as crucial. Doctor's instant instinct was to control blood sugar levels. As we all know, diabetes has been the cause of many reversible and irreversible changes, angiopathy and neuropathy to name a few. These conditions are a result of metabolic imbalance of advanced glycated end products [6] (glycated proteins and lipid when exposed to high levels of glucose and other sugars) deposited in nerves and due to the involvement of small blood vessel [7]. Compromised blood supply to this area can be a potential cause. Literatures have said that various metabolic disorders such as Hyperglycemia can cause chorea as well as seizure disorder [8].

The point of discussion will be how an antiepileptic drug played a role in absolute remission of the symptoms. Primidone is a Barbiturate, with anticonvulsant properties. It works via interactions with voltage gated sodium channels which inhibit high frequency repetitive firing of action potential. It is primarily used for focal epileptic seizures. It is a structural analogue of phenobarbital. It is approved for adjunctive or monotherapy for simple and complex partial seizures $[9,10]$ essential tremors [11] and some behavioral disorders [12]. In our patient we were able to achieve desired effect with the use of this drug. It should be advisable to use this drug as an adjunctive therapy in patients with hyperglycemia related hemichorea.

\section{Conclusion}

We presented a case of chorea as a presenting symptom in patients with hyperglycemia. Correction of aberrant glucose levels lead to amelioration of the patient's chorea suggesting that tight sugar control is effective in preventing these symptoms. In addition to this barbiturates such as Primidone prove effective in choreas induced by metabolic disturbance in blood.

\section{References}

1. Pant D, Singh A, Van Bogaert G, Olsen SI, Nigam PS, et al. (2012) Bioelectrochemical systems (BES) for sustainable energy production and product recovery from organic wastes and industrial wastewaters. RSC Adv 2(4): 1248-1263.

2. Clauwaert P, Van der Ha D, Boon N, Verbeken K, Verhaege M, et al. (2007) Open air biocathode enables effective electricity generation with microbial fuel cells. Environ Sci Technol 41(21): 7564-7569.

3. Rozendal RA, Hamelers HV, Euverink GJ, Metz SJ, Buisman CJ (2006) Principle and perspectives of hydrogen production through biocatalyzed electrolysis. Int J Hydrogen Energy 31(12): 1632-1640.

4. Aulenta F, Canosa A, Majone M, Panero S, Reale P, et al. (2008) Trichloroethenedechlorination and $\mathrm{H} 2$ evolution are alternative biological pathways of electric charge utilization by a dechlorinating culture in a bioelectrochemical system. Environ Sci Technol 42(16): 6185-6190.

5. Aulenta F, Canosa A, Reale P, Rossetti S, Panero S, et al. (2009) Microbial reductive dechlorination of trichloroethene to ethene with electrodes serving as electron donors without the external addition of redox mediators. Biotechnol Bioeng 103(1): 85-91.

6. Aulenta F, Canosa A, De Roma L, Reale P, Panero S, et al. (2009) Influence of mediator immobilization on the electrochemically assisted microbial dechlorination of trichloroethene (TCE) and cisdichloroethene (cis- DCE). J Chem Technol Biotechnol 84(6): 864-870. 
7. Clauwaert P, Rabaey K, Aelterman P, de Schamphelaire L, Pham TH, et al. (2007) Biological denitrification in microbial fuel cells. Environ Sci Technol 41(9): 3354-3360.

8. Choi 0, Sang BI (2016) Extracellular electron transfer from cathode to microbes: application for biofuel production. Biotechnol. Biofuels 9(1): 11 .

9. Kumar G, Saratale RG, Kadier A, Sivagurunathan P, Zhen G, et al (2017) A review on bio-electrochemical systems (BES) for the syngas and value added biochemicals production. Chemosphere 177: 84 -92.

10. Geppert F, Liu D, van Eerten-Jansen M, Weidner E, Buisman C, et al. (2016) Bioelectrochemical power to gas: State of the art and future perspectives. Trends Biotechnol 34(11): 879-894.

11. Cheng S, Logan BE (2007) Sustainable and efficient biohydrogen production via electro hydrogenesis. Proc Natl Acad Sci 104(47): 18871-18873.

12. Xafenian N, Mapelli V (2014) Performance and bacterial enrichment of bioelectrochemical systems during methane and acetate production. Int J Hydrogen Energy 39(36): 21864 - 21875.

13. Cheng S, Xing D, Call DF, Logan BE (2009) Direct biological conversion of electrical current into methane by electromethanogenesis. Environ Sci Technol 43(10): 3953 - 3958.

14. Kracke F, Vassilev I, Krömer JO (2015) Microbial electron transport and energy conservation - the foundation for optimizing bioelectrochemical systems. Front Microbiol 6: 575.

15. Patil SA, Hägerhäll C, Gorton L (2012) Electron transfer mechanisms between microorganisms and electrodes in bioelectrochemical systems. Bioanal Rev 4(2-4): 159-192.
16. Clauwaert P, Verstraete W (2009) Methanogenesis in membraneless microbial electrolysis cells. Appl Microbiol Biotechnol 82(5): 829.

17. Villano M, Aulenta F, Ciucci C, Ferri T, Giuliano A, et al. (2010) Bioelectrochemical reduction of $\mathrm{CO}_{2}$ to $\mathrm{CH} 4$ via direct and indirect extracellular electron transfer by a hydrogenophilic methanogenic culture. Bioresource Technol 101(9): 3085-3090.

18. Mao X, Stenuit B, Polasko A, Alvarez-Cohen L (2015) Efficient metabolic exchange and electron transfer within a syntrophictrichloroethenedegrading coculture of Dehalococcoidesmccartyi 195 and Syntrophomonaswolfei. Appl Environ Microbiol 81(6): 2015-2024.

19. Lovley DR (2011) Reach out and touch someone: potential impact of DIET (direct interspecies energy transfer) on anaerobic biogeochemistry, bioremediation, and bioenergy. Rev Environ Sci Biotechnol 10: 101-105.

20. Shrestha PM, Rotaru AE, Aklujkar M, Liu F, Shrestha M, et al. (2013) Syntrophic growth with direct interspecies electron transfer as the primary mechanism for energy exchange. Environ Microbiol Rep 5(6): 904-910.

21. Rotaru AE, Shrestha PM, Liu F, Markovaite B, Chen, S, et al. (2014) Direct interspecies electron transfer between Geobactermetallireducens and Methanosarcinabarkeri. Appl Environ Microbiol 80: 4599-4605.

22. Rotaru AE, Shrestha PM, Liu FH, Shrestha M, Shrestha D, Embree M, et al. (2014) A new model for electron flow during anaerobic digestion: direct interspecies electron transfer to Methanosaeta for the reduction of carbon dioxide to methane. Energy Environ Sci 7(1): 408-415.

Your next submission with Juniper Publishers will reach you the below assets

- Quality Editorial service

- Swift Peer Review

- Reprints availability

- E-prints Service

- Manuscript Podcast for convenient understanding

- Global attainment for your research

- Manuscript accessibility in different formats ( Pdf, E-pub, Full Text, Audio)

- Unceasing customer service

Track the below URL for one-step submission https://juniperpublishers.com/online-submission.php 